\title{
Aluminium Nanofluids Stability: A Comparison between the Conventional Two-Step Fabrication Approach and the Controlled Sonication Bath Temperature Method
}

\author{
Naser Ali $\mathbb{D}^{1,2}$ Joao A. Teixeira, ${ }^{1}$ and Abdulmajid Addali ${ }^{1}$ \\ ${ }^{1}$ Cranfield University, School of Aerospace, Transport and Manufacturing (SATM), Cranfield, England MK430AL, UK \\ ${ }^{2}$ Nanotechnology and Advanced Materials Program, Energy and Building Research Center, Kuwait Institute for Scientific Research, \\ Safat 13109, Kuwait \\ Correspondence should be addressed to Naser Ali; nmali@kisr.edu.kw
}

Received 18 July 2019; Accepted 26 August 2019; Published 27 October 2019

Academic Editor: William Yu

Copyright ( 2019 Naser Ali et al. This is an open access article distributed under the Creative Commons Attribution License, which permits unrestricted use, distribution, and reproduction in any medium, provided the original work is properly cited.

\begin{abstract}
This study investigates the shelving stability of dispersed aluminium nanoparticles in water mixtures fabricated by the conventional and the controlled bath temperature two-step methods. The nanofluids were prepared with water of $\mathrm{pH} 9$ and nanoparticles of $0.1-1.0$ vol.\%. A bath type ultrasonicator was employed for dispersing the nanoparticles into the base fluid. The sonication process, for all as-prepared samples, lasted for 4 hours and was either device bath temperature uncontrolled or controlled in the range of 10-60 $0^{\circ}$. Furthermore, the stability of the as-produced nanosuspensions was evaluated using the sedimentation photograph capturing method by capturing images at equal intervals of time for 12 hours then analysing the data based on the sample sedimentation height ratios. It was found that the sedimentation behaviour of the nanofluids fabricated via the controlled temperatures of less than $30^{\circ} \mathrm{C}$ was of dispersed sedimentation type, while those produced by the conventional method and the fixed temperatures of $30^{\circ} \mathrm{C}$ and higher were of flocculated sedimentation type. In addition, increasing the controlled sonication temperature has shown to increase the settling process of the sediments. Moreover, the rise in nanoparticle concentration was seen to reduce the variation in sedimentation height ratio between the fixed temperature samples. A comparison between the two fabrication methods has shown that the $30^{\circ} \mathrm{C}$ nanofluids had better short- and long-term stability than the conventionally produced suspensions.
\end{abstract}

\section{Introduction}

Aluminium (Al) is one of the most abundant crystal metals found on earth, which due to its capability of being fully recyclable, it is considered as a very sustainable material. The element itself and its alloys possess valuable electrical, mechanical, and thermal properties, which make their usages in various fields, such as construction and building, electrical engineering, and packaging favourable to the industry. Because of its relatively low density of $2700 \mathrm{~kg} / \mathrm{m}^{3}, \mathrm{Al}$ is known to be the lightest among most, if not all, commonly used metals [1]. The low density and promising properties of $\mathrm{Al}$ have, for long time, attracted manufacturers, especially in the automotive sector, to employ this element in fabricating their constructions and machined parts, so that the overall weight of the vehicles can be significantly reduced, and hence, the fuel consumption and $\mathrm{CO}_{2}$ emissions consequently get reduced alongside [2]. On the nanoscale, colloidal solutions containing $\mathrm{Al}$ nanoparticles (NPs) or its oxides (known as nanofluids) have been frequently reported as promising advanced working fluids that exceed conventional liquids in their heat transfer performance [3]. This is because the nanofluid effective thermal conductivity, which is the net thermal conductivity of the mixture, is seen to have a value within the range of the particles and the hosting fluid thermal conductivities. The highest effective thermal conductivity in any fabricated nanofluid can be achieved by optimizing the colloidal stability, which means that the dispersion of NPs needs to be maintained in a homogeneous manner at all time; 

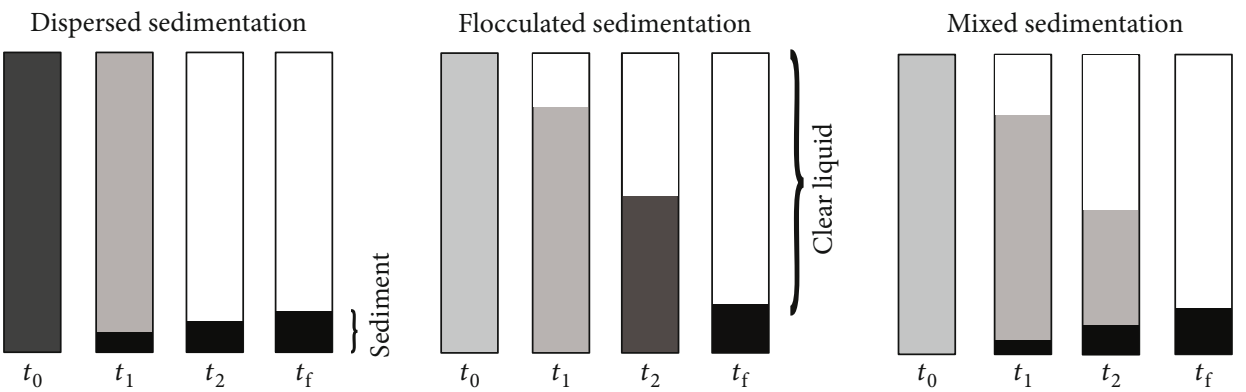

Figure 1: Forms of sedimentation mechanism in unstable nanofluids, where $t$ represent the settling time and $t_{0}<t_{1}<t_{2}<t_{\mathrm{f}}[6]$.

otherwise, its thermal, along with the physical, properties will gradually degrade [4].

Often this is hardly even possible, as one of the main challenges that is associated with nanofluids is their poor stability, whereby the NPs tend to attract each other into forming different sizes of clusters of particles or agglomerations. The reason behind such attraction behaviour was previously found to be due to the imbalance between the electrostatic repulsion force caused by the electrical double layers on the particle large surface area and the strong van der Waals force of attraction among the NPs [5].

Furthermore, the gravitational force tends to separate the agglomerated particles from the base fluid causing the sediments to settle at the bottom of the hosting fluid, and hence, the kinetic stability of the nanofluid gets negatively impacted. There are three types of sedimentation behaviours that can be observed in any unstable nanofluid [6], which are (1) dispersed sedimentation, (2) flocculated sedimentation, and (3) mixed sedimentation. An illustration of the three different types of sedimentation behaviours is shown in Figure 1.

Several methods were developed to evaluate the stability of nanofluids, such as (1) zeta potential analysis, (2) centrifugation method, (3) spectral analysis approach, (4) $3 \omega$-method, (5) electron microscopy analysis, and (6) sedimentation photograph capturing method [4]. From all of the aforementioned evaluation approaches, the sedimentation photograph capturing method is considered to be the simplest, cheapest, and is a reliable approach for measuring nanofluid stability $[7,8]$. In this technique, images of the change in sedimentation settling behaviour, due to gravitational force, are captured within equal intervals of time; thus, visual estimation of nanofluid shelf-life can therefore be obtained [9]. It is important to note that this approach is considered as a qualitative method rather than a quantitative one. On the other hand, the parameters that influence the stability of any fabricated nanofluids are the type of nanomaterial used, concentration, particle size, morphology, and density of the solid particles, as well as the kind of base fluid used and its temperature; while the shape and size of the cluster depend greatly on the liquid $\mathrm{pH}$ value, surfactant (if added), sonication power intensity, and duration of mixing. Modifying one or more of the previously mentioned parameters can help in improving the homogeneity and dispersion of the NPs within the nanofluid.

Our review of the available literature $[10,11]$ has shown that, when using an ultrasonicator for preparing nanofluids, the device bath temperature gradually rises with time, and that the highest temperature is constrained by the surrounding atmospheric conditions of the site. This fact needs to be factored in when considering the reproducibility and commercial production of the nanofluids in large scale as different ultrasonic devices and/or surrounding atmospheric conditions would lead to varying the thermophysical properties and stability of the fabricated colloid.

Therefore, in this study, an evaluation of the stability of dispersed Al NPs in water fabricated via the conventional two-step method and the controlled sonication bath temperature approaches was performed. The sedimentation photograph capturing method was employed to determine the nanofluid stability variation with time. The examined nanofluids were prepared at equal sonication time using different concentrations of NPs, in the range of $0.1-1.0$ vol.\%. Furthermore, for the controlled temperature method, the ultrasonicator bath temperature was fixed at a set of temperatures of $10^{\circ} \mathrm{C}$ to $60^{\circ} \mathrm{C}$, while the conventional fabrication route was initiated at room temperature conditions. Stability monitoring for all as-prepared samples lasted for the same duration of time. The outcome of this research is expected to widen the understanding of both researchers and manufactures of the significant and importance role of the production process on the stability of nanofluids.

\section{Experimental Procedure}

2.1. Materials. A purity of $99.9 \% \mathrm{Al}$ nanoparticles, of spherical particle shape and size between 40 and $60 \mathrm{~nm}$, were purchased from SkySpring Nanomaterials Incorporated. A set of $60 \mathrm{~mL}$ clear glass vials, of $27.5 \mathrm{~mm}$ outer diameter and $140 \mathrm{~mm}$ height, with screwed top were provided by Sigma-Aldrich. Polypropylene holed caps, which include a polytetrafluoroethylene (PTFE)/silicone septa for each, were obtained from Sigma-Aldrich to seal the aforementioned vials. Deionised water, produced by an Elga PR030BPM1-US Purelab Prima 30 water purification system, was used as the base fluid for the nanofluid preparation after adjusting its $\mathrm{pH}$ value to 9 , at an in-lab temperature of $25^{\circ} \mathrm{C}$. The reason behind selecting the liquid $\mathrm{pH}$ value to be 9 is because other authors have reported high alumina nanofluid stability when using water of $\mathrm{pH} \leq 8[12-14]$. Therefore, a $\mathrm{pH}$ of 9 would provide an unstable nanofluid that is close to the stability level, which will enable us to conduct our research investigation. Modification of the water $\mathrm{pH}$ was achieved by adding sodium 


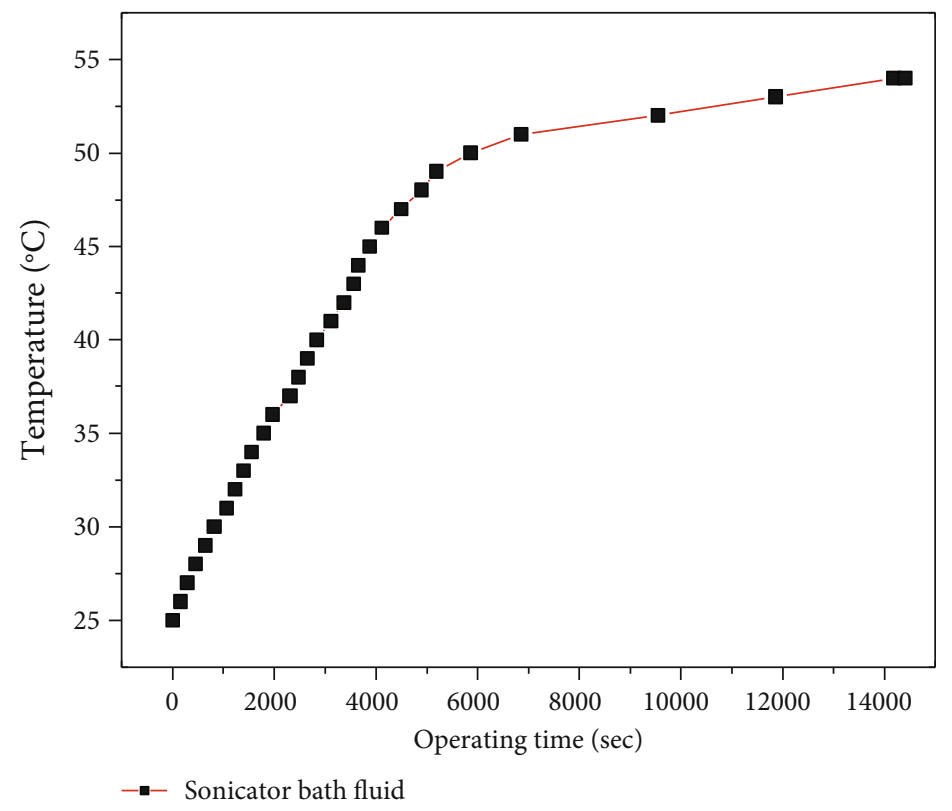

FIGURE 2: Ultrasonicator bath temperature changes with operation time.

hydroxide $(\mathrm{NaOH})$ solution $\left(1.09956\right.$, Titrisol $\left.{ }^{\circledR}\right)$ to the liquid, while been monitored by a calibrated HACH HQ11D portable $\mathrm{pH}$ meter that is connected to a PHC20101 Intellical gel-filled $\mathrm{pH}$ electrode. The accuracy of the $\mathrm{pH}$ meter, as reported by the manufacturer, is of $\pm 0.002 \mathrm{pH}$, and the initial calibration of the device was performed using commercial calibration fluids of $\mathrm{pH} 4,7$, and 10 that were purchased from Metrohm USA Incorporated.

2.2. Nanoparticle Characterization. Elemental test was performed for the Al NPs through a $9 \mathrm{~kW}$ Rigaku SmartLab, Japan, and X-ray diffraction (XRD) analyser and its software, SmartLab Guidance, using a $\mathrm{CuK} \alpha \mathrm{X}$-ray source with a diffraction angle of $2 \theta$ and an incidence beam step of $0.2^{\circ}$ to determine the Bragg's peaks of the elements contained in the examined sample. The diffraction scanning angle range was from $20^{\circ}$ to $80^{\circ}$, with a scanning rate of $1^{\circ} / \mathrm{min}$. A JEOL JSM-6010LA InTouchScope ${ }^{\mathrm{TM}}$ scanning electron microscopy (SEM) device and its integrated energy dispersive X-ray spectroscopy (EDS) analyser were used to check the morphology, size, and level of oxidisation of the as-received $\mathrm{Al}$ powder. The SEM images were recorded at two different magnifications by the secondary electron mode from the surface region of the tested sample. It is important to note that the SEM and EDS analyses were conducted at a working distance of $10 \mathrm{~mm}$ from the sample with an accelerating voltage of $20 \mathrm{kV}$ to reduce any possible damages to the examined powder, and that the operating software used was InTouchScope 1.12. The density of the NPs $\left(\rho_{n p}\right)$ was obtained to calculate the $\mathrm{Al}$ powder volumetric concentration, which is part of the nanofluid fabrication process requirement. This was done by first measuring the $\mathrm{Al}$ sample weight, using an aeADAM PW 214 analytical balance of $0.0001 \mathrm{~g}$ readability and $\pm 0.0002 \mathrm{~g}$ accuracy. Then, the weighted powder was placed inside a HumiPyc ${ }^{\mathrm{TM}}$ Model 1 gas pycnometervolumetric analyser, which operated at $25^{\circ} \mathrm{C}$, to obtain the density of the sample from its input mass and the volume measured by the instrument.

2.3. Nanofluid Fabrication. Each nanofluid sample was prepared by placing the NPs first inside the vial then injecting $20 \mathrm{~mL}$ of as-prepared water, using a disposable syringe, on top of the nanopowder after which the vial was tightly sealed using the provided caps. The concentrations of NPs used were $0.1,0.5$, and 1.0 vol. $\%$, for each experimental setup, which was calculated by using the mixing theory (Equations (1) and (2)) that is widely used by many researchers in the field $[4,15]$.

$$
\begin{aligned}
V_{n p} & =\frac{m_{n p}}{\rho_{n p}}, \\
f_{V} & =\frac{V_{n p}}{V_{n p}+V_{b f}},
\end{aligned}
$$

where $f_{V}, V_{n p}, V_{b f}$, and $m_{n p}$ are the NP concentration, volume of NPs, volume of base fluid, and mass of NPs, respectively. The vial containing the solution was then placed gently in a Soniclean Company benchtop bath type ultrasonic vibrator, running at $100 \%$ power $(43 \mathrm{kHz}$ pulse) and filled with water to the recommended operating level by the manufacturer, to agitate the mixture. This kind of particle dispersion method is known as the two-step approach, which is a common procedure used for the production of nanofluids by many researchers $[4,16]$. The fabrication process then took one of the following two routes: (1) conventional two-step method, where the sonicator bath temperature initially starts at $25^{\circ} \mathrm{C}$ and ends at $54^{\circ} \mathrm{C}$, without external interference (Figure 2); and (2) controlled temperature two-step approach, where the device bath temperature was controlled for a set of temperatures from $10^{\circ} \mathrm{C}$ to $60^{\circ} \mathrm{C}$, with a margin of $\pm 1^{\circ} \mathrm{C}$. It is worth noting that the 


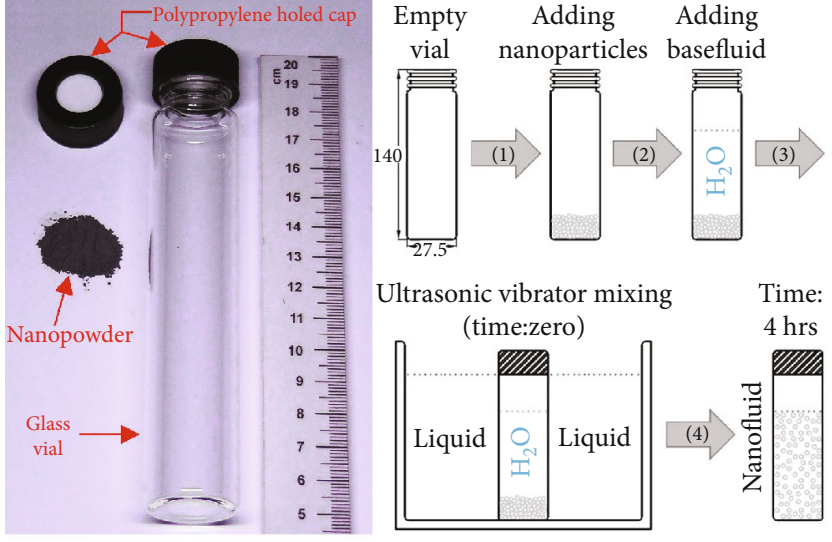

Figure 3: Schematic procedure for the two-step nanofluid preparation.

lab temperature where the nanofluid preparations were conducted at was $25^{\circ} \mathrm{C}$, surfactants or dispersing materials/chemicals were not used, sonication duration was 4 hours for all as-fabricated nanofluids, and the bath temperature was maintained by gradually adding hot or cold water inside the ultrasonic tank and extracting any access water from the device via the attached ejection valve. Figure 3 demonstrates the schematic procedure used for the nanofluid preparation.

2.4. Stability Measurements. To determine the natural settling behaviour of the nanosuspensions, the as-sonicated nanofluids were placed individually on a measuring stand to allow the separation mechanism to take place under gravitational force after which their sedimentation heights were measured with respect to time by capturing their photographical images, using a Canon EOS 700D professional camera that is equipped with a Sigma $105 \mathrm{~mm}$ F2.8 EX DG micro lens and a Phottix Company TR-90 remote switch with digital timer, at the start then for every 30 seconds for a total duration of 12 hours. The configuration used for the stability measurements is shown in Figure 4. Sediment height ratio (SHR) was later calculated in terms of the average sediment height $\left(H_{S}\right)$ (i.e., the average of both left and right sides of the sediment) and total liquid height $\left(H_{T}\right)$, as illustrated in Equation (3).

$$
\operatorname{SHR}=\frac{H_{S}}{H_{T}} .
$$

The accuracy of the two previously mentioned heights (i.e., $H_{S}$ and $H_{T}$ ) was within $\pm 0.5 \mathrm{~mm}$. Furthermore, a comparison between the different preparation methods was performed, via the obtained SHR's, to evaluate the nanofluid natural settling behaviour with time.

\section{Results and Discussion}

3.1. X-Ray Diffraction Analysis. The diffraction pattern of the as-received Al NPs is shown in Figure 5. It can be observed from the analysis, at angles $2 \theta=20.46^{\circ}, 40.80^{\circ}$, and $48.82^{\circ}$, that the $\mathrm{Al}$ sample contains some traces of oxidation. The

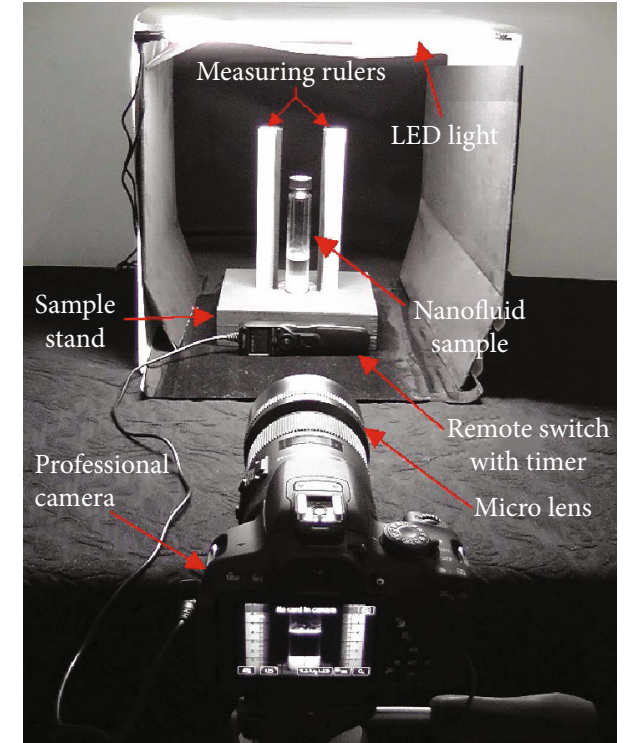

FIGURE 4: Setup for nanofluid stability measurement.

aforementioned angles are indexed in the XRD pattern as (020), (041), and (042), respectively. Furthermore, the crystallite sizes $\left(D_{h k l}\right)$ of the highest peaks of $\mathrm{Al}$ and $\alpha-\mathrm{Al}_{2} \mathrm{O}_{3}$ have shown to be about $50 \mathrm{~nm}$, at (111), and $91 \mathrm{~nm}$, at (042), respectively. The $D_{h k l}$ values were obtained using the Scherrer formula [17-20], which is demonstrated in Equation (4).

$$
D_{h k l}=\frac{F \lambda}{\beta_{h k l} \cos \theta_{h k l}},
$$

where $F$ represents a constant value of $0.9, \lambda$ signifies the wavelength of the $\mathrm{CuK} \alpha \mathrm{X}$-ray radiation source and is equal to $0.15405 \mathrm{~nm}, \beta_{h k l}$ is the full width at half the maximum of the $(h k l)$ diffraction peak, and $\theta_{h k l}$ is the Bragg angle at the $(h k l)$ peak.

3.2. Aluminium Nanoparticle Morphology, Level of Oxidisation, and Density. The SEM analysis of the asreceived nanopowder has shown that the morphology of the examined NPs is of spherical shape and that some agglomerations between the particles do exist, as illustrated by the SEM patterns (Figures 6(a) and 6(b)). Moreover, the size of the particles was seen to be roughly in the range of 50 to $95 \mathrm{~nm}$. The observed growth in some of the NP sizes (i.e., larger than the reported by the manufacturer) is due to the formation of $\alpha-\mathrm{Al}_{2} \mathrm{O}_{3}$ caused by the unavoidable exposure of the sample to the surrounding atmosphere, when performing the characterisation tests. This was also confirmed by the previous XRD analysis and the EDS X-ray spectrum (Figure 6(c)), which shows the present of oxygen within the specimen. The EDS elemental percentages of the characterised nanopowder are tabulated in Table 1. Furthermore, the measured density of the Al NPs was found to be $3.22 \mathrm{~g} / \mathrm{cm}^{3}$, with a standard deviation of $0.81 \times 10^{-2} \mathrm{~g} / \mathrm{cm}^{3}$. Thus, using Equations (1) and (2), the amounts of NPs 


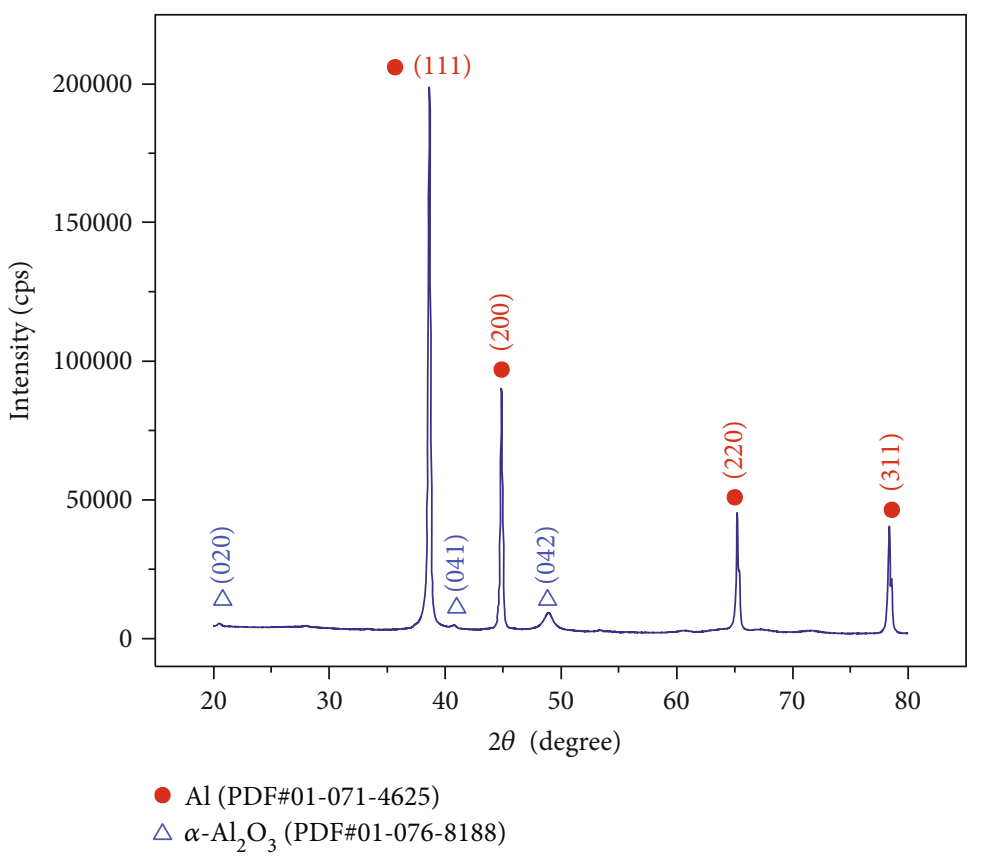

FIGURE 5: X-ray diffraction patterns of as-received aluminium nanoparticles.

required to fabricate the $0.1,0.5$, and $1.0 \mathrm{vol} . \%$ of nanofluids with $20 \mathrm{~mL}$ of water are 64, 323, and $650 \mathrm{mg}$, respectively.

3.3. Nanofluid Settling Behaviour. Settling characterisation of the as-fabricated nanofluids has shown two types of sedimentation behaviours, which are the dispersed sedimentation and the flocculated sedimentation. The dispersed sedimentation was observed by the nanofluids prepared with 0.1 and 1.0 vol. \% at controlled temperatures of $10^{\circ} \mathrm{C}$ and $20^{\circ} \mathrm{C}$, while the other samples have illustrated a flocculated sedimentation settling mechanism. Such variation in settling behaviour is believed to be caused by the timing of NPs oxidation, where the reaction rate of the particles starts to prominently increase, within the aforementioned samples of dispersed sedimentation, after the sonication phase, in contrast to the nanofluids of flocculated sedimentation behaviour which most of its particles oxidise during the preparation stage. This is clearly seen by the notable hydrogen generation in the nanofluids that had experienced a dispersed sedimentation mechanism in comparison to the other as-fabricated suspensions. The hydrogen production is due to the following two possible reactions between the Al NPs and the hosting solution.

$$
\begin{gathered}
\mathrm{Al}+3 \mathrm{H}_{2} \mathrm{O}+\mathrm{NaOH} \longrightarrow \mathrm{NaAl}(\mathrm{OH})_{4}+3 / 2 \mathrm{H}_{2} \\
\mathrm{NaAl}(\mathrm{OH})_{4} \longrightarrow \mathrm{Al}(\mathrm{OH})_{3}+\mathrm{NaOH}
\end{gathered}
$$

Equations (5) and (6) can be summed up into the following overall reaction.

$$
\mathrm{Al}+3 \mathrm{H}_{2} \mathrm{O} \longrightarrow \mathrm{Al}(\mathrm{OH})_{3}+3 / 2 \mathrm{H}_{2}
$$

An example of the two previous settling behaviours is demonstrated in Figure 7, and an in-depth discussion and explanation of the significant role of water temperature on the hydrogen production rate from dispersing $\mathrm{Al}$ can be found in Hiraki et al. published work [21].

Furthermore, the changes in the SHR of the as-prepared nanofluids during the photographical analysis are shown in Figure 8. It can be seen that the settling data of the nanofluids sonicated at controlled $10-20^{\circ} \mathrm{C}$ has a different trend behaviour than the suspensions that were fabricated with higher temperatures. This is expected and is associated with, as previously mentioned, the different types of sedimentation mechanism formed due to the timing of the highest oxidation rate occurrence within the samples. It was also found that rising the fabrication temperature, of the 0.1 and 0.5 vol.\% nanofluids, caused the NP settling mechanism to escalate (Figures 8(a) and 8(b)) and hence increases the separation between the water molecules and the hosted NPs. In addition, the SHR was seen to rapidly decrease at the early stages of the nanofluid shelving time, reaching values as low as 0.44 and 0.47 within $64 \mathrm{~min}$, for the 0.1 and 0.5 vol.\% suspensions produced at $60^{\circ} \mathrm{C}$, respectively. Such observation is expected in most nanofluids and is known as the rapid settling region, as reported by other researchers $[4,22]$. In general, there exist two phase separation speed regions; the first is the previously introduced rapid settling region and the one beyond it is called the slow settling region, where the settling speed highly reduces along the shelving time period. On the other hand, the effect of sonication temperatures, between 30 and $60^{\circ} \mathrm{C}$, on the suspensions of higher NP concentration (i.e., 1.0 vol.\%), has shown to have less influence on the stability of the as-prepared nanofluids (Figure $8(\mathrm{c})$ ). The divergence in SHR between the conventional method and the controlled 


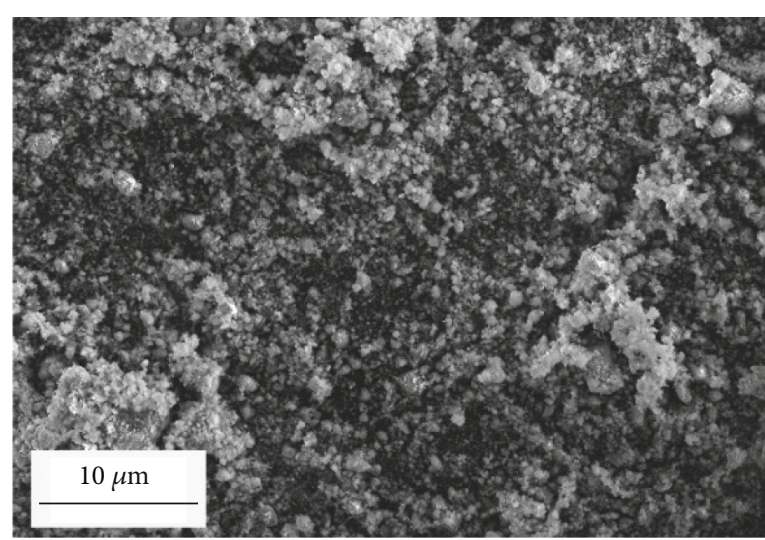

(a)

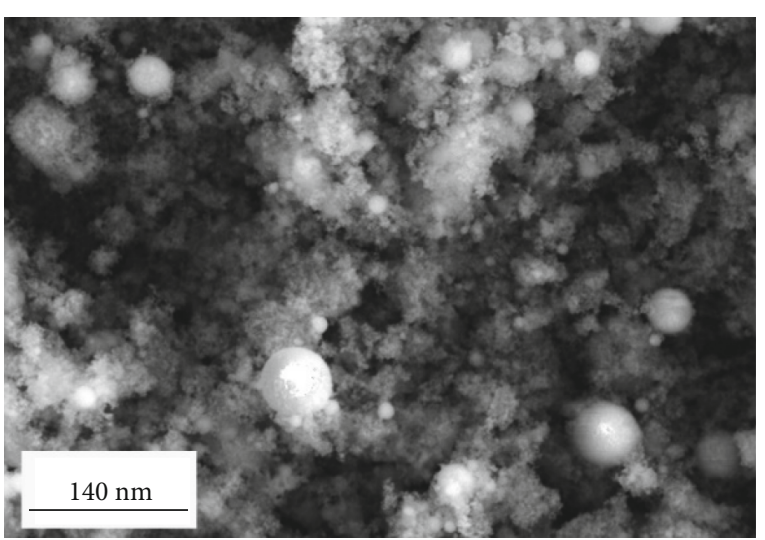

(b)

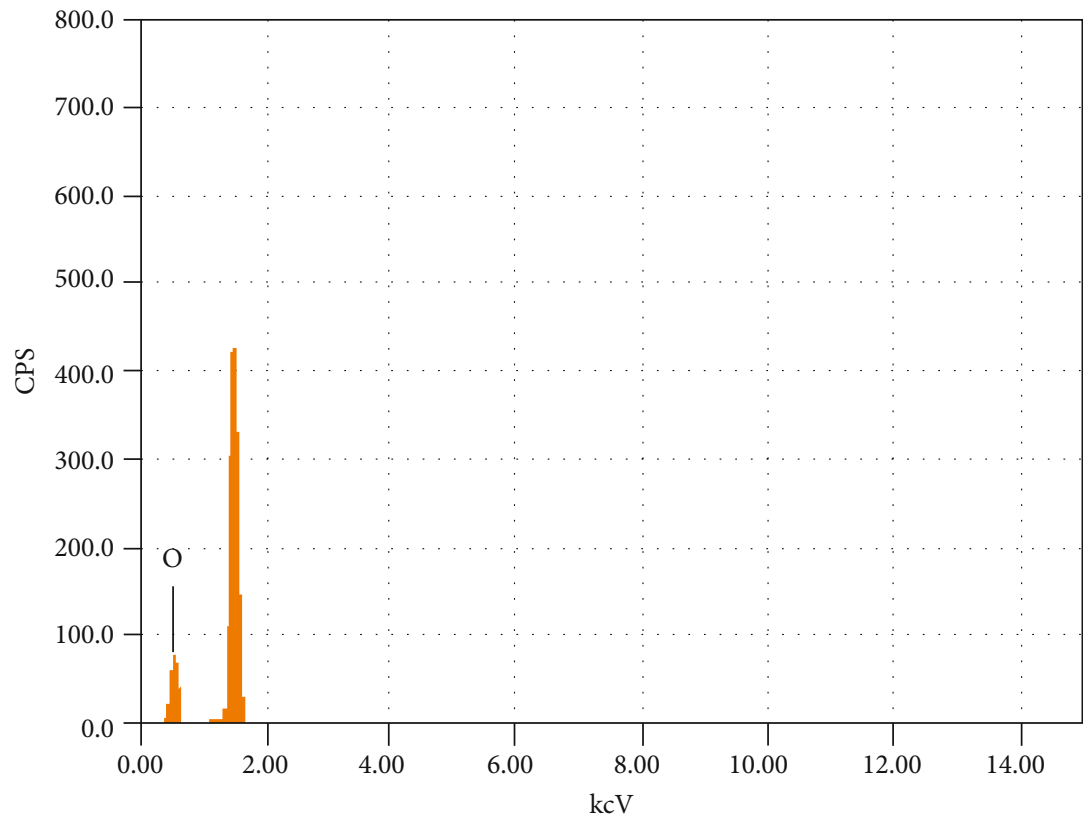

(c)

FIGURE 6: SEM and EDS analysis of the as-received Al nanopowder, where ( $\mathrm{a}, \mathrm{b})$ are the SEM images of the sample at low and high magnifications, respectively, and (c) is the EDS X-ray spectrum of the elements within the characterised specimen.

TABLE 1: EDS elemental percentage of the as-received $\mathrm{Al}$ nanopowder.

\begin{tabular}{lccccc}
\hline Element & Mass (\%) & Atom (\%) & Sigma & Net & $K$ ratio \\
\hline Aluminium & 62.35 & 49.55 & 0.09 & 1582595 & 0.3617546 \\
Oxygen & 37.65 & 50.45 & 0.07 & 210593 & 0.1499887 \\
Total & 100 & 100 & - & - & - \\
\hline
\end{tabular}

temperature approach for the nanofluids, of 1.0 vol. $\%$, has shown to be at the end of the settling experiment (i.e., at time $720 \mathrm{~min})-44.4 \%\left(10^{\circ} \mathrm{C}\right),-31.3 \%\left(20^{\circ} \mathrm{C}\right),+10 \%\left(30^{\circ} \mathrm{C}\right),-6.1 \%$ $\left(40^{\circ} \mathrm{C}\right),-2.2 \%\left(50^{\circ} \mathrm{C}\right)$, and $+2.3 \%\left(60^{\circ} \mathrm{C}\right)$ than the nanosuspension of uncontrolled bath temperature.

In general, the nanofluids that were fabricated at $30^{\circ} \mathrm{C}$ have demonstrated better short- and long-term stability than the ones produced by the conventional two-step approach, as illustrated by the data in Figure 8 and the photographical images shown in Figure 9, with the advantage of being reproducible at different atmospheric conditions, as this is not possible with the uncontrolled temperature scheme.

\section{Conclusion}

Water-based colloid containing dispersed Al nanoparticles has been characterised via the sedimentation photograph capturing method to emphasize the role of the fabrication approach on the stability of the mixture. Two procedures were undertaken for the production of the as-prepared nanofluids, which are the conventional two-step approach and the two-step controlled sonication bath temperature method. The parameters studied include the nanoparticle concentration, nanofluid fabrication temperature, and sediment height ratio in the fluid. 


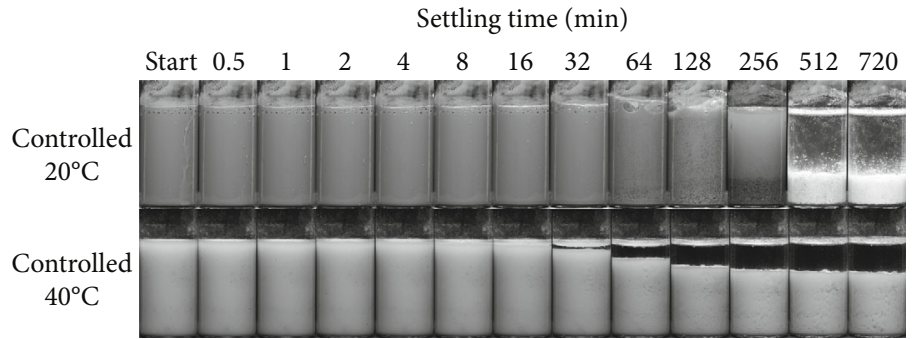

Figure 7: Settling behaviour of the 0.5 vol.\% nanofluids fabricated by a controlled ultrasonicator bath temperature of $20^{\circ} \mathrm{C}$ (top) and $40^{\circ} \mathrm{C}$ (bottom).

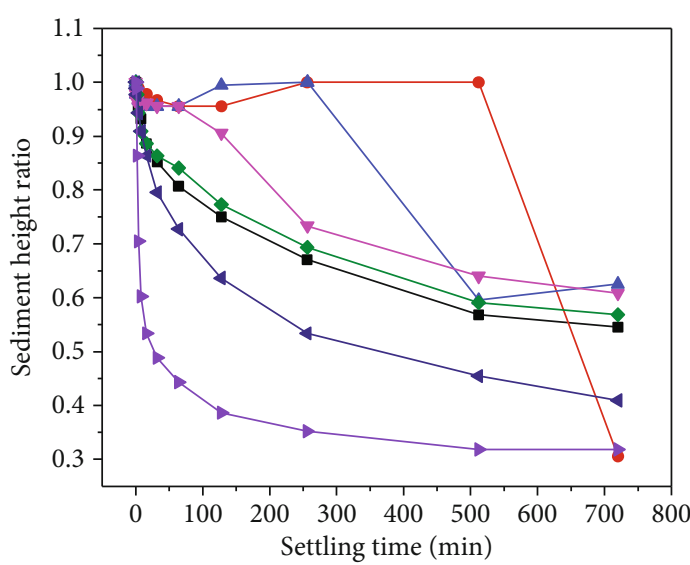

- Uncontrolled sonication temperature

$\rightarrow$ Fabrication temperature $10^{\circ} \mathrm{C}$

$\rightarrow$ Fabrication temperature $20^{\circ} \mathrm{C}$

$\rightarrow$ Fabrication temperature $30^{\circ} \mathrm{C}$

$\rightarrow$ Fabrication temperature $40^{\circ} \mathrm{C}$

$\leftarrow$ Fabrication temperature $50^{\circ} \mathrm{C}$

$\rightarrow$ Fabrication temperature $60^{\circ} \mathrm{C}$

(a)

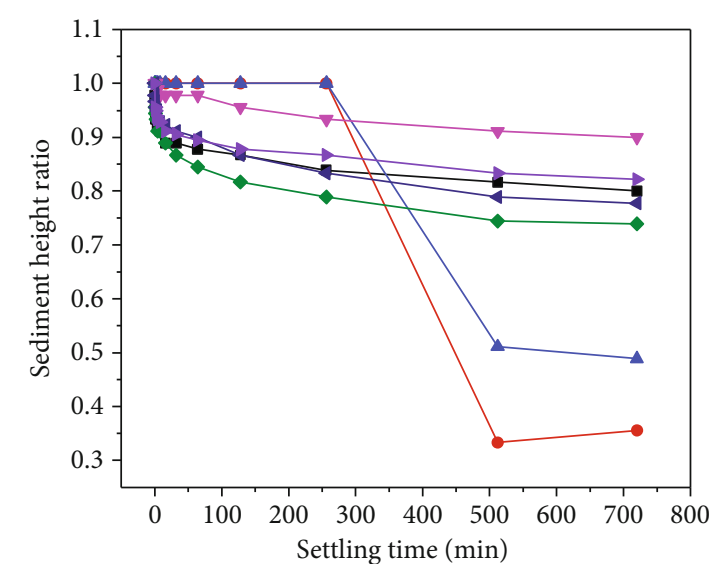

- Uncontrolled sonication temperature

$\rightarrow$ Fabrication temperature $10^{\circ} \mathrm{C}$

- Fabrication temperature $20^{\circ} \mathrm{C}$

$\rightarrow$ Fabrication temperature $30^{\circ} \mathrm{C}$

$\multimap$ Fabrication temperature $40^{\circ} \mathrm{C}$

$\longleftarrow$ Fabrication temperature $50^{\circ} \mathrm{C}$

$\rightarrow-$ Fabrication temperature $60^{\circ} \mathrm{C}$

(c)

Figure 8: Sediment height ratio variation with settling time for the nanofluids fabricated with (a) 0.1 vol.\%, (b) 0.5 vol.\%, and (c) 1.0 vol.\%. 


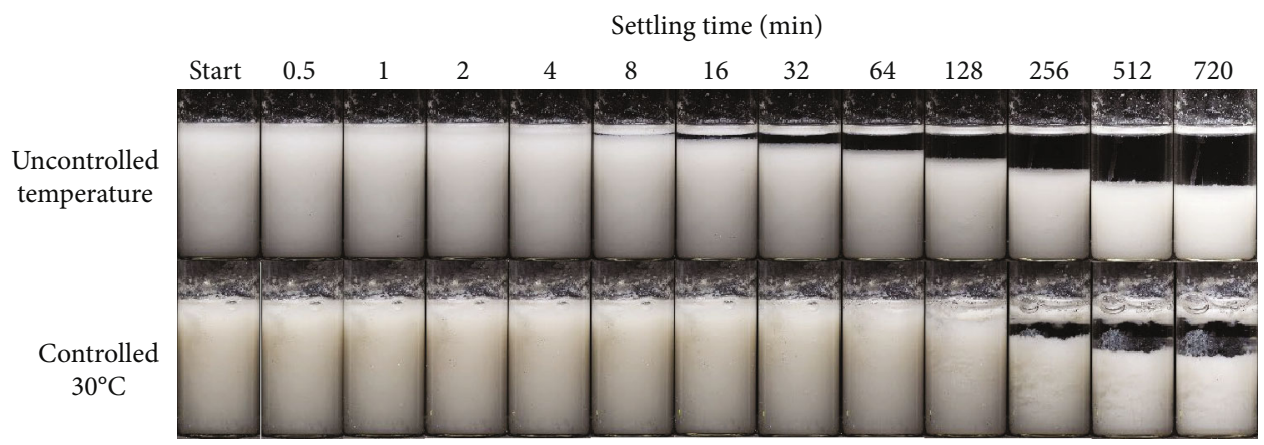

(a)

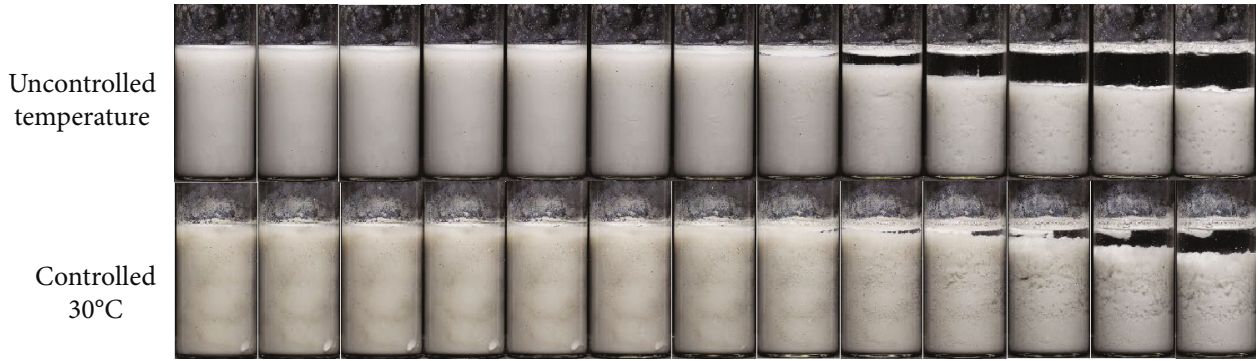

(b)

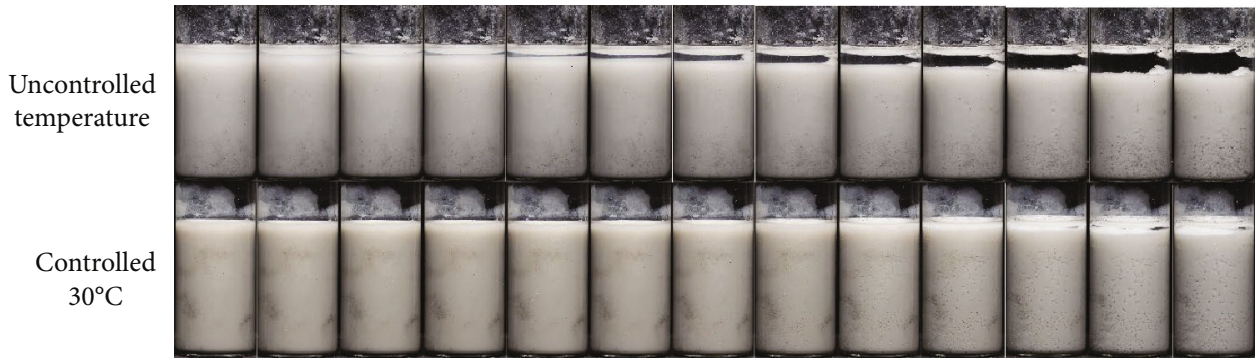

(c)

FIGURE 9: Photographical images of the nanofluid settling behaviour with time using the uncontrolled and $30^{\circ} \mathrm{C}$ controlled sonication temperature approaches, where the NP concentrations used were (a) 0.1 vol.\%, (b) 0.5 vol.\%, and (c) 1.0 vol.\%.

Sodium hydroxide was used to adjust the $\mathrm{pH}$ value of the base fluid to 9 , as lower $\mathrm{pH}$ values were reported in the literature to highly stabilise similar types of nanofluids. Mixing of the colloid was performed using an ultrasonic bath type device to induce the dispersion of the particles. It was found that the conventional two-step approach caused the bath temperature to increase with time, thus confirming other researchers' findings. Moreover, the experiments have revealed that nanofluids produced at controlled temperatures lower than $30^{\circ} \mathrm{C}$ follow a dispersed sedimentation behaviour, whereas those fabricated at $30^{\circ} \mathrm{C}$ and above obeyed a flocculated sedimentation settling mechanism.

Evaluation of the nanofluids prepared by the controlled temperature method has generally shown a decrease in their stability with the increase in fabrication temperature. In addition, the increase in nanoparticle concentration has shown to reduce the variation in sedimentation height ratio between the samples that were produced at different fixed temperatures. Furthermore, when comparing the nanofluids fabricated by the two aforementioned preparation methods, it was seen that the stability of the $30^{\circ} \mathrm{C}$ colloid has exceeded all other controlled temperature samples, which obeyed the same sedimentation mechanism, beyond the rapid settling region. The $30^{\circ} \mathrm{C}$ nanosuspensions have also demonstrated better short- and long-term stability behaviour than the conventionally fabricated nanofluids. Thus, confirming that the controlled temperature two-step nanofluid fabrication approach is much promising in terms of the colloidal shelving stability than the conventional method.

\section{Data Availability}

The data used to support the findings of this study are available from the corresponding author upon request.

\section{Conflicts of Interest}

The authors declare no conflict of interest.

\section{Acknowledgments}

We acknowledge the help provided by Prof. M. Sherif El-Eskandarany, the program manager of Nanotechnology and Advanced Materials Program at KISR, for his help and support throughout the conducted work. This work was 
financially supported by the Kuwait Institute for Scientific Research (KISR) and Cranfield University.

\section{References}

[1] C. Vargel, "Chapter A.2 - physical properties of aluminium," in Corrosion of Aluminium, pp. 19-20, Elsevier, Amsterdam, 2004.

[2] J. Hirsch, "Recent development in aluminium for automotive applications," Transactions of Nonferrous Metals Society of China, vol. 24, no. 7, pp. 1995-2002, 2014.

[3] K. Farhana, K. Kadirgama, M. M. Rahman et al., "Significance of alumina in nanofluid technology," Journal of Thermal Analysis and Calorimetry, vol. 138, no. 2, pp. 1107-1126, 2019.

[4] N. Ali, J. A. Teixeira, and A. Addali, "A review on nanofluids: fabrication, stability, and thermophysical properties," Journal of Nanomaterials, vol. 2018, Article ID 6978130, 33 pages, 2018.

[5] F. Babick, K. Schießl, and M. Stintz, "van-der-Waals interaction between two fractal aggregates," Advanced Powder Technology, vol. 22, no. 2, pp. 220-225, 2011.

[6] S. U. Ilyas, R. Pendyala, and N. Marneni, "Settling characteristics of alumina nanoparticles in ethanol-water mixtures," in 2013 2nd International Conference on Advanced Materials Design and Mechanics, ICAMDM 2013, pp. 143-148, Scientific.Net, Kuala Lumpur, 2013.

[7] X. Li, D. Zhu, and X. Wang, "Evaluation on dispersion behavior of the aqueous copper nano-suspensions," Journal of Colloid and Interface Science, vol. 310, no. 2, pp. 456-463, 2007.

[8] X. Wei and L. Wang, "Synthesis and thermal conductivity of microfluidic copper nanofluids," Particuology, vol. 8, no. 3, pp. 262-271, 2010.

[9] S. U. Ilyas, R. Pendyala, and N. Marneni, "Stability and agglomeration of alumina nanoparticles in ethanol-water mixtures," in 4th International Conference on Process Engineering and Advanced Materials, ICPEAM 2016, M. A. Bustam, L. K. Keong, Z. Man, A. A. Hassankiadeh, and Y. Y. Fong, Eds., pp. 290-297, Elsevier Ltd, 2016.

[10] Y. Y. Song, H. K. D. H. Bhadeshia, and D.-W. Suh, "Stability of stainless-steel nanoparticle and water mixtures," Powder Technology, vol. 272, pp. 34-44, 2015.

[11] A. Naser, J. A. Teixeira, and A. Addali, "New pH correlations for stainless steel $316 \mathrm{~L}$, alumina, and copper(I) oxide nanofluids fabricated at controlled sonication temperatures," Journal of Nano Research, vol. 58, pp. 125-138, 2019.

[12] A. Ghadimi, R. Saidur, and H. S. C. Metselaar, "A review of nanofluid stability properties and characterization in stationary conditions," International Journal of Heat and Mass Transfer, vol. 54, no. 17-18, pp. 4051-4068, 2011.

[13] School of Mechanical Engineering, KIIT University, Bhubaneswar-751024, Odisha, India and S. Mukherjee, "Preparation and stability of nanofluids-a review," IOSR Journal of Mechanical and Civil Engineering, vol. 9, no. 2, pp. 63-69, 2013.

[14] S. Manjula, S. M. Kumar, A. M. Raichur, G. M. Madhu, R. Suresh, and M. A. L. A. Raj, "A sedimentation study to optimize the dispersion of alumina nanoparticles in water," Cerâmica, vol. 51, no. 318, pp. 121-127, 2005.

[15] B. C. Pak and Y. I. Cho, "Hydrodynamic and heat transfer study of dispersed fluids with submicron metallic oxide parti- cles," Experimental Heat Transfer, vol. 11, no. 2, pp. 151-170, 1998.

[16] W. Yu and H. Xie, "A review on nanofluids: preparation, stability mechanisms, and applications," Journal of Nanomaterials, vol. 2012, Article ID 435873, 17 pages, 2012.

[17] X. Ai, J. Lin, Y. Chang, L. Zhou, X. Zhang, and G. Qin, "Phase modification of copper phthalocyanine semiconductor by converting powder to thin film," Applied Surface Science, vol. 428, pp. 788-792, 2018.

[18] P. V. Raleaooa, A. Roodt, G. G. Mhlongo, D. E. Motaung, and O. M. Ntwaeaborwa, "Analysis of the structure, particle morphology and photoluminescent properties of ZnS:Mn2+ nanoparticulate phosphors," Optik, vol. 153, pp. 31-42, 2018.

[19] M. Rabiee, H. Mirzadeh, and A. Ataie, "Processing of $\mathrm{Cu}-\mathrm{Fe}$ and $\mathrm{Cu}-\mathrm{Fe}-\mathrm{SiC}$ nanocomposites by mechanical alloying," Advanced Powder Technology, vol. 28, no. 8, pp. 1882-1887, 2017.

[20] S. Minaei, M. Haghighi, N. Jodeiri, H. Ajamein, and M. Abdollahifar, "Urea-nitrates combustion preparation of $\mathrm{CeO}_{2}$-promoted $\mathrm{CuO} / \mathrm{ZnO} / \mathrm{Al}_{2} \mathrm{O}_{3}$ nanocatalyst for fuel cell grade hydrogen production via methanol steam reforming," Advanced Powder Technology, vol. 28, no. 3, pp. 842-853, 2017.

[21] T. Hiraki, M. Takeuchi, M. Hisa, and T. Akiyama, "Hydrogen production from waste aluminum at different temperatures, with LCA," Materials Transactions, vol. 46, no. 5, pp. 1052 1057, 2005.

[22] S. Witharana, C. Hodges, D. Xu, X. Lai, and Y. Ding, "Aggregation and settling in aqueous polydisperse alumina nanoparticle suspensions," Journal of Nanoparticle Research, vol. 14, no. 5, 2012. 


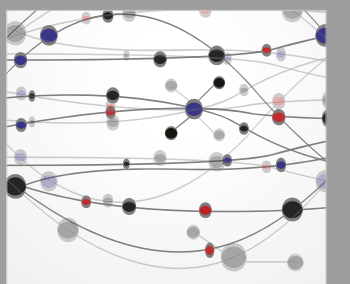

The Scientific World Journal
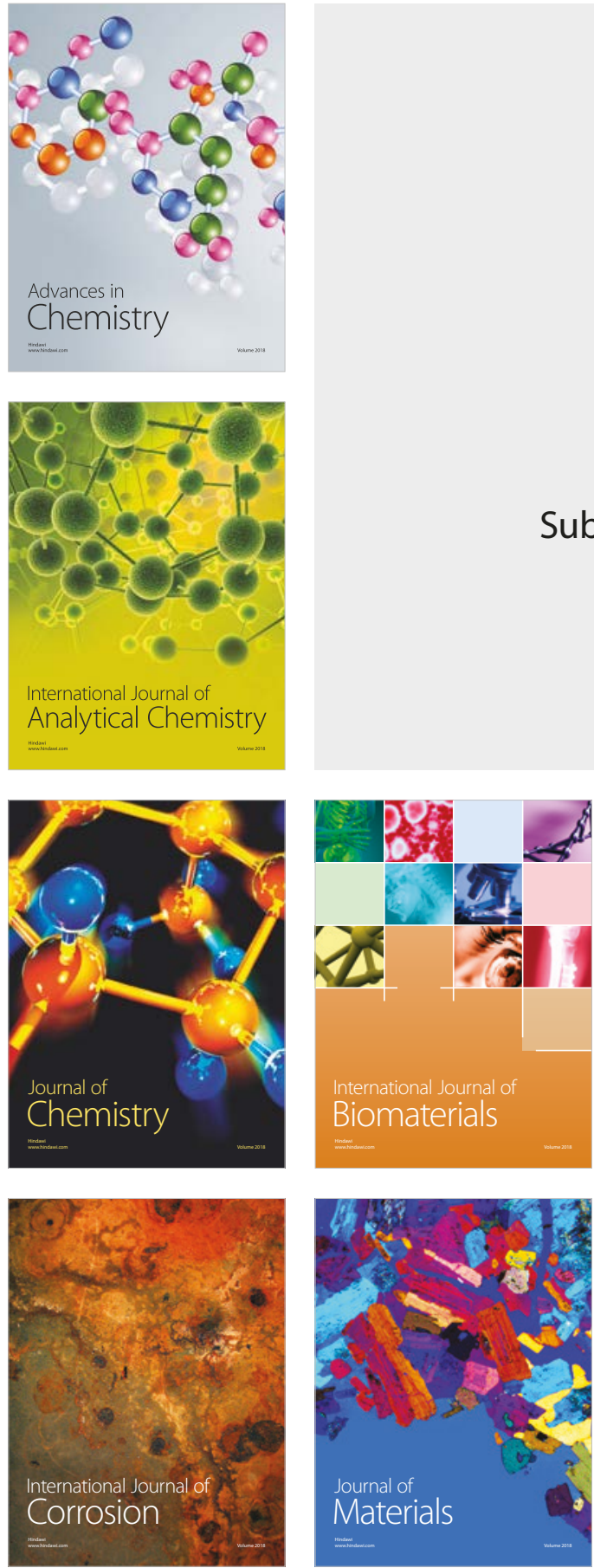

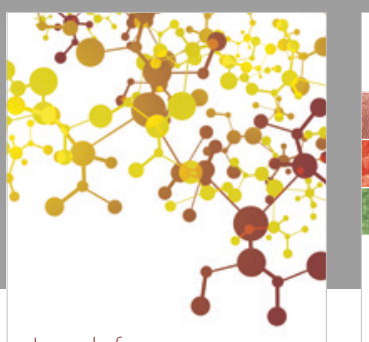

Journal of

Applied Chemistry
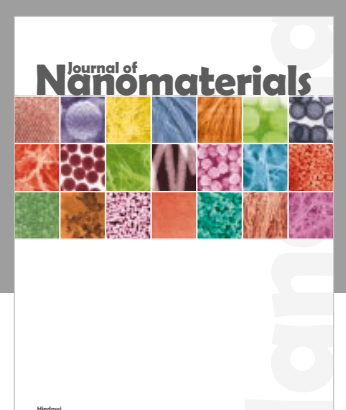

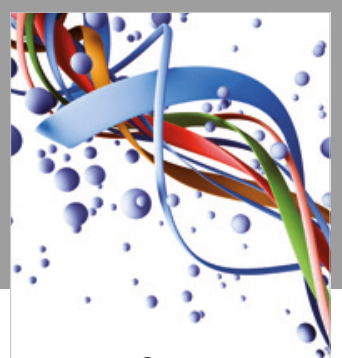

Scientifica

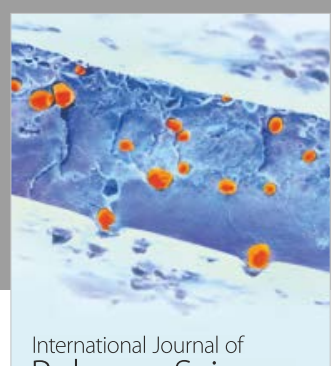

Polymer Science

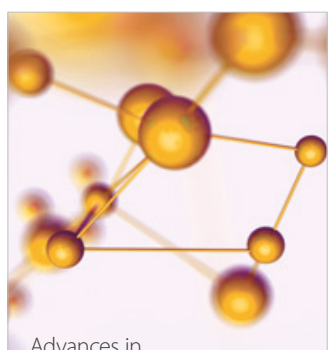

Physical Chemistry
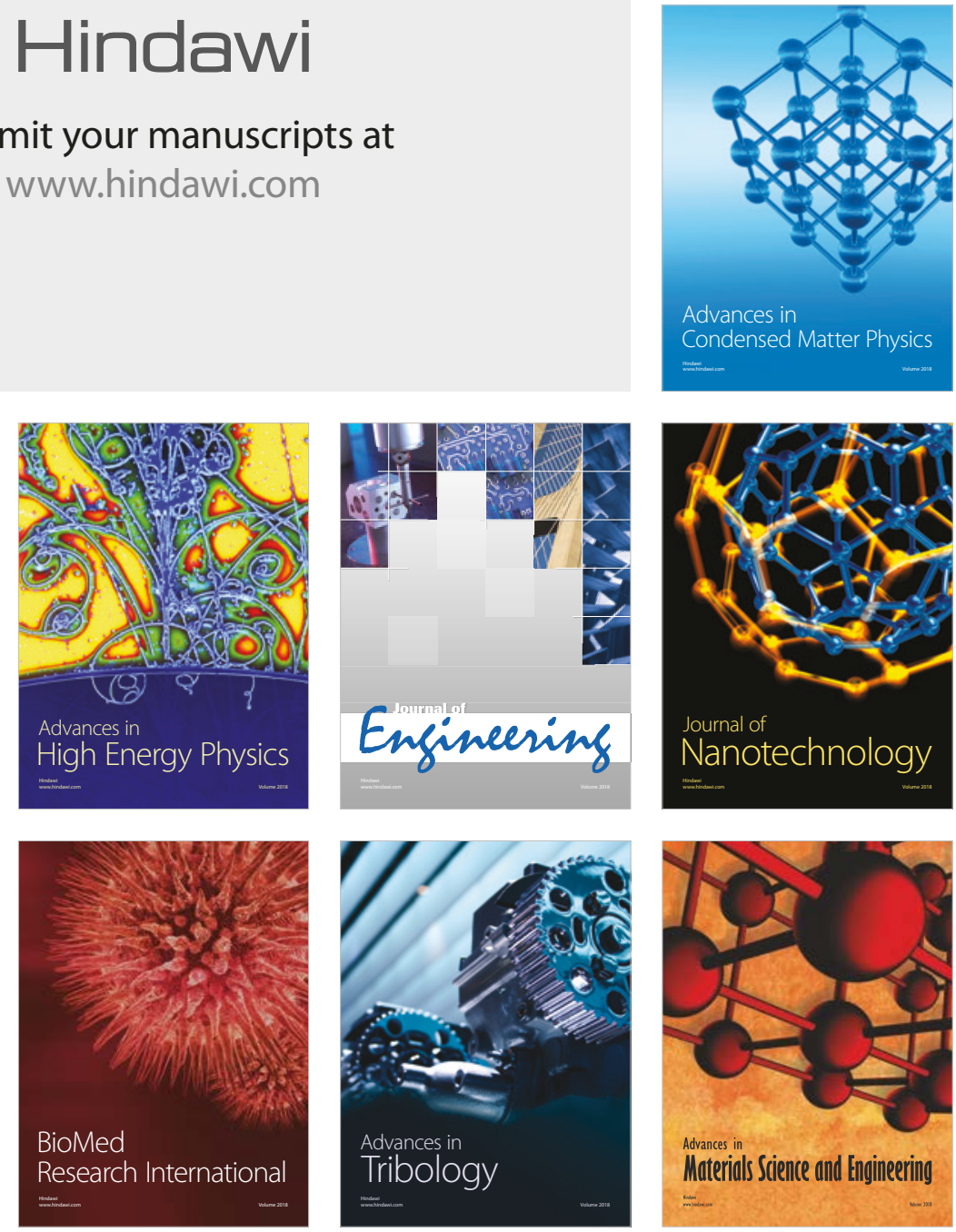